\title{
New insights into clinical features, karyotypes, and age at diagnosis in women with Turner syndrome
}

\author{
Jakub Frelich ${ }^{1,2}$, Tomasz Irzyniec ${ }^{1,3}$, Katarzyna Lepska ${ }^{1}$, Wacław Jeż $\dot{z}^{1}$ \\ ${ }^{1}$ Department of Health Promotion and Community Nursing, Faculty of Health Sciences, Medical University of Silesia, \\ Katowice, Poland \\ ${ }^{2}$ Department of Nephrology/ENDO Hospital of the Ministry of Interior and Administration, Katowice, Poland \\ ${ }^{3}$ Outpatient Clinic for Women with Turner Syndrome, Specialist Hospital No. 2, Bytom, Poland
}

\begin{abstract}
Introduction: Turner syndrome (TS) is due to a chromosomal abnormality in which only one normal X chromosome is present. The purpose of the study was the assessment the prevalence of phenotypic differences in TS-women and monosomy-45,X and with other karyotypes as well as the possible relationship between the presence of differentiating features and age at final TS diagnosis.

Material and methods: The prevalence of anomalies and abnormalities from history taking/physical examination of 157 TS-patients was compared to 25 healthy controls (age $27.3 \pm 4.5$ years). The age at TS-symptom occurrence and final TS diagnosis was also analysed. Results: Ninety-three TS women with 45,X (25.2 $\pm 7.1 \mathrm{y})$ and 64 with other karyotypes (non-45,X) (age $24.1 \pm 8.2$ years) had lower growth than controls (144 \pm 7.6 and $145.7 \pm 6.8$ vs. $165.8 \pm 6.6 \mathrm{~cm}$, respectively; $\mathrm{p}<0.001$ ). Only 15 and 12 out of 37 non-gynaecological features occurred more frequently in $45, X$ and non- $45, X$, compared to controls. $45, X$ and non- $45, X$ wpmen did not differ in terms of body height. Out of 60 study parameters, only nine differed significantly between 45,X TS women and those with other karyotypes. Mean age at TS-symptom occurrence (45,X: $6.8 \pm 5.4$ years; non- $45, X: 10.3 \pm 5.2$ years; $\mathrm{p}<0.001)$ and final TS diagnosis $(45, \mathrm{X}: 13.2 \pm 8$ years; non $45, X: 17 \pm 8.2$ years; $p=0.004)$ differed between TS groups.

Conclusions: 1 . The prevalence of the majority of clinical manifestations of Turner syndrome does not differ between TS women with $45, X$ monosomy and non-45, $X$ karyotypes. 2. Certain manifestations of Turner syndrome are more prevalent in women with non- $45, X$ karyotypes compared to those with 45,X monosomy. 3. Clinical manifestations, the prevalence of which differs between TS-women with non-45,X karyotypes and 45,X monosomy, might help lower the age at diagnosis. (Endokrynol Pol 2019; 70 (4): 342-349)
\end{abstract}

Key words: Turner syndrome; clinical features; phenotype; karyotype; age at diagnosis

\section{Introduction}

Turner syndrome (TS) is due to a chromosomal abnormality in which only one normal $X$ chromosome is present. Its aetiology is still unknown $[1,2]$. Turner syndrome includes a wide variety of chromosomal karyotypes and clinical phenotypes [3]. A majority of TS features are due to reduced dosage of genes on the short arm of the $X$ chromosome (Xp) [4]. Because TS is associated with a wide variety of anatomical and physiological abnormalities, its phenotypic presentation is highly variable and has not been ultimately determined [5-7]. Physical stigmata can be quite subtle or absent, and this phenotypic variability of TS remains challenging for clinicians [8, 9[. Basic phenotypic abnormalities occur in the tissues of mesodermal origin [10]. Clinical manifestations found in TS females can either be attributed to chromosome $X$ abnormality or gonadal dysgenesis. Treatment-related symptoms cannot entirely be excluded either. Because there are no pathognomonic features of Turner syndrome, the disorder should be considered in any female with short stature or delayed puberty [11].

Life expectancy of women with TS is shorter than that of the general population, mainly due to cardiovascular pathologies [12]. Despite progress in the diagnosis as well as treatment of organ abnormalities and clinical sequelae thereof, premature mortality remains a major problem. In adult females, the diagnosis of TS complications is frequently delayed [13]. There is also no clear-cut evidence to suggest that TS women with $45, X$ monosomy are at greater risk of morbidity or mortality than women with other karyotypes. Several investigations, including the present study, have focused on these issues [14]. For instance, Lebenthal et al. [15] analysed metabolic comorbidities in TS patients and attempted to determine whether their occurrence differed between $45, X$ monosomy and other karyotypes. Nevertheless, a range of issues regarding diagnosis, treatment, rehabilitation, and the overall approach to patients with Turner syndrome remain unsolved [16]. 
The aim of the study was to determine the following: - the prevalence of phenotypic differences in TS patients with 45,X monosomy and those with other karyotypes as established on history taking and physical examination;

- the possible relationship between the presence of clinical features differentiating 45, $X$ monosomy from other karyotypes and the age at symptom emergence and final diagnosis of TS.

The results may have practical implications. Nielsen and Wohlert [17] studied sex chromosome abnormalities and found that TS occurred in one per 2130 girls. In Poland there are approximately 8000 females with Turner syndrome, of whom 5000 are over 18 years old. In a large proportion of this population the diagnosis was significantly delayed. Therefore the identification of clinical features that emerge early enough to facilitate diagnosis might help lower the age at final diagnosis of Turner syndrome and, consequently, accelerate treatment initiation, prevent complications, and improve quality of life and life satisfaction.

\section{Material and methods}

The study population comprised 157 patients with TS including 93 women diagnosed with 45,X monosomy and 64 women with other karyotypes (non- $45, X)$. The control group comprised 25 healthy women of the general population. The study groups did not differ with respect to age $(25.2 \pm 7.14$ and $24.1 \pm 8.24$ years, respectively) the proportion of participants who had received growth hormone therapy in their childhood (20.4 and $17.2 \%$, respectively), or the proportion of women presently on hormone replacement therapy (HRT) (52.7 and 54.7\%, respectively).

The diagnosis of TS was confirmed by karyotyping using cytogenetic and advanced molecular analysis [13]. Features to be assessed were selected based on literature descriptions of tissue and organ abnormalities seen in TS women [18-20]. The following 36 nongynaecological clinical features were evaluated prospectively based on each patient's medical history and records: systemic diseases (history of thyroid diseases, arterial hypertension, diabetes mellitus - three features), ear, nose and throat (ENT) and maxillofacial surgery (feeding problems during infancy, low-set and/or deformed ears, hearing loss, otitis media, surgery for otitis media, oral cavity soft tissue abnormalities, third tonsil surgery, high-arched palate - eight features), dentistry (dental caries and tooth loss, dental braces, malocclusion, retrognathism - four features), ophthalmology (history of vision defects, drooping eyelids, epicanthal folds, dense eyebrows, long eyelashes, squint, daltonism - seven features), dermatology [childhood lymphoedema, history of skin diseases, neck anomalies (short/webbed), low posterior hairline, facial hypertrichosis, fingernail anomalies - six feature], cardiology (heart defect(s), history of cardiosurgery, blood pressure $\geq 140 / 90 \mathrm{~mm} \mathrm{Hg}$ - three features), urology and nephrology (urinary system malformations, urologic surgery, conservative kidney management - three features), and orthopaedic (finger/toe deformity and posture defects - two features). Including body height there were 37 features altogether.

A total of 23 endocrine-obstetric-gynaecological features were determined based on predisposing factors identified in literature. These include parental consanguinity, intoxication during pregnancy, premature birth, differences in birth weight and length, amenorrhoea pubertal delay and induction, menstruation delay and induction, gradual loss of menstrual cycles, Tanner stage, hirsutism, virilisation, and use of HRT, growth hormone (GH), and oxandrolone. The prevalence of abnormal cervicovaginal cytology test and surgical interventions was assessed as well as the history of miscarriages, the occurrence of symptoms, and age at menopause. The study participants, from the whole of Poland, were examined from March 1995 to September 2015 in Poland's only "de nomine" outpatient clinic for women with Turner syndrome. The investigations were conducted by the same group of investigators over a period of 20 years in Bytom and Katowice. All participants gave their consent to study procedures, all of which were approved by the Bioethics Committee. The prevalence of anomalies and abnormalities found on history taking/physical examination of women with Turner syndrome and $45, \mathrm{X}$ monosomy or other karyotypes is presented in table form. There were 36 non-gynaecological parameters grouped according to the above-mentioned areas of interest. The prevalence of the majority of these features was compared between each of the study groups and the controls. These 36 parameters plus the above-mentioned endocrine-obstetric-gynaecological features $(\mathrm{n}=$ 23) and body height resulted in a total of 60 study parameters. An analysis of parameter prevalence and mean values (in the case of quantitative parameters, e.g. birth length and weight) enabled us to identify features differentiating between TS women with $45, X$ and those with other karyotypes.

The age at TS-symptom occurrence and final TS diagnosis was also noted.

The mean age at symptom occurrence and final diagnosis of Turner syndrome was determined in TS women who exhibited the features differentiating between the $45, \mathrm{X}$ and non- $45, \mathrm{X}$ karyotypes. This was done in an attempt to establish possible relationships between these features and age at symptom occurrence and final TS diagnosis.

The statistical analysis was carried out using Statistica 12 software (StatSoft Inc., Palo Alto, CA, USA). The results are presented as the mean \pm standard deviation (SD). The results were compared with the unpaired t-test. The bilateral test of differences between two structural indicators was applied to evaluate the number of occurrences of a particular value. The level of statistical significance was set at $\mathrm{p}<0.05$

\section{Results}

Ninety-three (59.3\%) women with TS had simple 45,X monosomy while $64(40.7 \%)$ had other, non- 45 ,X karyotypes. The following karyotypes were revealed in the non-45,X group: 18 (11.5\%) women with structural abnormalities of the $\mathrm{X}$ chromosome (e.g. isochromosome $X$, partial deletion of an arm of the $X$ chromosome, ring $\mathrm{X}$ chromosome or translocation between the $\mathrm{X}$ chromosome and the autosomal material); another subgroup of $46(29.3 \%)$ patients had mosaic karyotypes [24 (15.3\%) mosaicism without structural chromosome abnormality: seven with X monosomy and normal male cell line, 15 with $X$ monosomy and normal female cell line, two with $\mathrm{X}$ monosomy and an aneuploid female cell line — trisomy] and 22 (14\%) mosaicism with a second cell line with structural chromosome $\mathrm{X}$ abnormality.

\section{TS groups vs. controls}

TS women with $45, X$ monosomy and with non- $45, X$ karyotypes had significantly shorter stature compared to the general population ( $144 \pm 7.6$ and $145.7 \pm 6.8 \mathrm{~cm}$ vs. $165.8 \pm 6.6 \mathrm{~cm}$, respectively; $\mathrm{p}<0.001)$. The controls and TS women with $45, \mathrm{X}$ monosomy differed significantly with respect to the prevalence of webbed neck, 
childhood lymphoedema, dense eyebrows and long lashes, drooping eyelids, epicanthal folds, abnormalities of the shape and position of the pinna, middle ear infections and hearing impairment, feeding problems during infancy, unusual palatal configurations, and retrognathism. TS women also showed a lower prevalence of dental anomalies. TS women with non- $45, X$ karyotypes did not differ significantly with respect to arterial hypertension (two parameters) and the history of childhood lymphoedema compared to the control group. Compared to the controls, only 15 and 12 out of 37 non-gynaecological features under analysis were found in TS-women with 45,X monosomy and non- $45, \mathrm{X}$ karyotypes, respectively (Tab. I).

Table I. Abnormalities revealed on history taking and physical examination in women with Turner syndrome and 45,X (A), other karyotypes $(B)$, and the control participants $(C)$

\begin{tabular}{|c|c|c|c|c|c|c|c|c|c|}
\hline \multirow{2}{*}{ Feature } & \multicolumn{2}{|c|}{$A(n=93)$} & \multicolumn{2}{|c|}{$B(n=64)$} & \multicolumn{2}{|c|}{$C(n=25)$} & \multicolumn{3}{|c|}{$\mathrm{p}$-value } \\
\hline & V & $(\%)$ & V & $(\%)$ & V & $(\%)$ & A vs. C & B vs. C & A vs. B \\
\hline Arterial hypertension & 28 & 30.1 & 11 & 17.2 & 0 & 0 & 0.017 & NS & NS \\
\hline Diabetes mellitus & 5 & 5.5 & 3 & 4.7 & 0 & 0 & NS & NS & NS \\
\hline History of thyroid diseases & 17 & 18.5 & 10 & 15.6 & 6 & 25 & NS & NS & NS \\
\hline Feeding problems during infancy & 50 & 55.6 & 38 & 64.4 & 3 & 12.5 & $<0.001$ & $<0.001$ & NS \\
\hline Low-set and/or deformed ears & 77 & 82.8 & 56 & 87.5 & 5 & 20 & $<0.001$ & $<0.001$ & NS \\
\hline Hearing loss & 29 & 31.2 & 22 & 34.3 & 2 & 8.3 & 0.024 & 0.014 & NS \\
\hline Otitis media & 64 & 68.8 & 42 & 66.7 & 9 & 37.5 & 0.005 & 0.014 & NS \\
\hline Surgery for otitis media & 11 & 11.8 & 4 & 6.3 & 0 & 0 & NS & NS & NS \\
\hline Oral cavity soft tissue abnormalities & 2 & 2.2 & 3 & 4.7 & 0 & 0 & NS & NS & NS \\
\hline Third tonsil adenoidectomy & 24 & 25.8 & 15 & 24.6 & 4 & 16.7 & NS & NS & NS \\
\hline High-arched palate & 83 & 89.3 & 53 & 82.8 & 0 & 0 & $<0.001$ & $<0.001$ & NS \\
\hline Dental caries and lost teeth & 6 & 6.5 & 4 & 6.3 & 13 & 54.2 & $<0.001$ & $<0.001$ & NS \\
\hline Dental braces & 17 & 18.3 & 9 & 14.1 & - & - & & & NS \\
\hline Malocclusion & 41 & 44.1 & 226 & 40.6 & 13 & 54.2 & NS & NS & NS \\
\hline Retrognathism & 58 & 62.4 & 36 & 56.3 & 5 & 20 & $<0.001$ & 0.004 & NS \\
\hline History of vision defects & 52 & 56.5 & 37 & 57.8 & 10 & 40 & NS & NS & NS \\
\hline Drooping eyelids & 48 & 51.6 & 30 & 46.9 & 2 & 8 & $<0.001$ & $<0.001$ & NS \\
\hline Epicanthal folds & 30 & 32.3 & 22 & 34.4 & 0 & 0 & $<0.001$ & $<0.001$ & NS \\
\hline Dense eyebrows, long eyelashes & 63 & 67.7 & 47 & 73.4 & 0 & 0 & $<0.001$ & $<0.001$ & NS \\
\hline Squint & 11 & 11.8 & & 17.2 & 1 & 4 & NS & NS & NS \\
\hline Daltonism & 0 & 0 & & 3.1 & 0 & 0 & & $\mathrm{n}$ & NS \\
\hline Childhood lymphoedema & 35 & 37.6 & & 14.3 & 1 & 4 & 0.0012 & NS & $<0.001$ \\
\hline History of skin disease & 22 & 23.9 & & 20.3 & 1 & 4 & 0.026 & 0.058 (NS) & NS \\
\hline Neck anomalies (short/webbed) & 61 & 65.6 & & 43.8 & 0 & 0 & $<0.001$ & $<0.001$ & 0.007 \\
\hline Low posterior hairline & 59 & 64.1 & & 46 & 1 & 4 & $<0.001$ & $<0.001$ & 0.0245 \\
\hline Facial hypertrichosis & 8 & 8.6 & & 6.3 & 1 & 4 & NS & NS & NS \\
\hline Fingernail anomalies & 48 & 51.6 & & 44.4 & - & & & & NS \\
\hline Heart defect(s) & 14 & 15.1 & & 7.8 & - & & & & NS \\
\hline History of cardiosurgery & 2 & 2.2 & & 4.7 & - & & & & NS \\
\hline Blood pressure $\geq 140 / 90 \mathrm{~mm} \mathrm{Hg}$ & 30 & 32.3 & & 32.8 & 0 & 0 & 0.014 & 0.011 & NS \\
\hline Urinary system malformations & 18 & 19.4 & & 12.5 & - & & & & NS \\
\hline Urologic surgery & 3 & 3.2 & & 3.2 & - & & & & NS \\
\hline Conservative kidney management & 26 & 28.3 & & 42.2 & - & & & & NS \\
\hline Posture defects & 49 & 52.7 & & 28.1 & - & & & & 0.002 \\
\hline Finger/toe deformity & 29 & 31.2 & & 15.9 & - & & & & 0.03 \\
\hline
\end{tabular}

$\mathrm{V}$ - absolute values; \% — percentage; NS — not significant; (-) no data 


\section{5,X monosomy vs. non-45, $X$ karyotypes}

Our TS-participants with 45,X monosomy were not significantly shorter than those with non- $45, \mathrm{X}$ karyotypes $(144 \pm 7.6$ and $145.7 \pm 6.8 \mathrm{~cm}$, respectively; $\mathrm{p}=0.133$ ). The respective birth lengths were $51.6 \pm 2.9$ and $49.7 \pm 4.9 \mathrm{~cm}$; the birth length of women with $45, \mathrm{X}$ monosomy was significantly greater $(\mathrm{p}=0.038)$. Birth weight $(2849.1 \pm 508.8$ and $2738.2 \pm 649.3 \mathrm{~g}$, respectively), age of puberty (15.7 \pm 1.6 and $15.7 \pm 3$ years, respectively), age at menarche ( $16.6 \pm 1.9$ and $17.2 \pm 5.2$ years, respectively), and age at menopause onset (21.1 \pm 8 and $19.7 \pm 6.5$ years, respectively) did not differ significantly between the groups. Out of 60 parameters analysed, nine differed significantly between TS women with $45, \mathrm{X}$ monosomy and those with other karyotypes. TS women with $45, X$ monosomy more frequently had: 1 . clinical records of childhood lymphoedema, 2. short and webbed neck, 3 . low posterior hairline, 4 . postural defects, and 5. finger/toe deformities (all compared to TS women with other karyotypes). The prevalence of
19 out of 23 endocrine-obstetric-gynaecological features (Tab. II) did not differ significantly between the two groups of women with TS. The differentiating features were: 1 . pubertal induction, 2 . menarche induction, 3 . proportion of gynaecological surgeries, and 4 . birth length. Only the first two features were more prevalent in $45, X$ monosomy.

\section{The mean age at TS-symptom occurrence and final diagnosis of Turner syndrome}

The mean age at TS-symptom occurrence $(45, \mathrm{X}$ monosomy $6.8 \pm 5.4$ years $v$ s. other karyotypes $10.3 \pm 5.2$ years; $\mathrm{p}<0.001$ ) and final diagnosis of Turner syndrome $(45, \mathrm{X}$ monosomy $-13.2 \pm 8$ years vs. non $45, \mathrm{X}-17 \pm 8.2$ years; $\mathrm{p}=0.004$ ) differed significantly between both study groups. The mean age at symptom development and final diagnosis of Turner syndrome in patients from both study groups with: clinically documented childhood lymphoedema, short and webbed neck, low posterior hairline, postural defects and finger/toe

Table II. The prevalence and severity of endocrine-obstetric-gynaecological features in 157 women with TS and 45,X monosomy or non- $45, X$ karyotypes

\begin{tabular}{|c|c|c|c|c|c|}
\hline \multirow{2}{*}{ Feature } & \multicolumn{2}{|c|}{$45, X(n=93)$} & \multicolumn{2}{|c|}{ non-45,X $(n=64)$} & \multirow{2}{*}{ p-value } \\
\hline & v & $(\%)$ & v & $(\%)$ & \\
\hline Parental consanguinity & 1 & 1.1 & 2 & 3.1 & NS \\
\hline Intoxication during pregnancy & 56 & 60.9 & 44 & 70 & NS \\
\hline Premature birth & 8 & 9 & 11 & 18 & NS \\
\hline Birth length [cm] & 51.6 & \pm 2.9 & 49.7 & \pm 4.9 & 0.038 \\
\hline Body weight at birth $[\mathrm{g}]$ & 2849 & \pm 509 & 2738 & \pm 649 & NS \\
\hline Amenorrhoea & 8 & 8.8 & 8 & 12.5 & NS \\
\hline Age at puberty [years] & 15.7 & \pm 1.6 & 15.7 & \pm 3 & NS \\
\hline Induced puberty & 55 & 59.1 & 26 & 41 & 0.023 \\
\hline Age at menarche [years] & 16.6 & \pm 1.9 & 17.2 & \pm 5.2 & NS \\
\hline Induced menarche & 75 & 88 & 39 & 69.5 & 0.006 \\
\hline Abnormal cervicovaginal cytology test & 16 & 17.2 & 8 & 12.5 & NS \\
\hline Tanner stage $<$ IV & 55 & 59 & 41 & 59.4 & NS \\
\hline Gynaecological surgeries & 7 & 7.5 & 11 & 17.2 & 0.008 \\
\hline Loss of menstrual cycle & 24 & 25.8 & 14 & 22 & NS \\
\hline No GH treatment in childhood & 71 & 79 & 50 & 85 & NS \\
\hline No oxandrolone therapy & 68 & 75.6 & 44 & 74.6 & NS \\
\hline No history of HRT & 7 & 7.3 & 3 & 5.1 & NS \\
\hline Hirsutism & 8 & 8.6 & 4 & 6.3 & NS \\
\hline Virilisation & 5 & 5.4 & 0 & 0 & 0.059 (NS) \\
\hline Miscarriages & 1 & 1.1 & 1 & 1.6 & NS \\
\hline Menopause symptoms & 21 & 22.7 & 24 & 37.5 & NS \\
\hline Menopause onset (years) & 21.1 & \pm 8 & 19.7 & \pm 6.5 & NS \\
\hline No current HRT & 40 & 47.1 & 25 & 41 & NS \\
\hline
\end{tabular}

GR — growth hormone; HRT — hormone replacement therapy; NS — not significant 
Table III. Mean age at Turner syndrome (TS) symptom occurrence and final diagnosis of TS, in TS women with $45, X$ monosomy - A, TS women with other karyotypes (non$45, X)-B$, as well as in TS women with phenotypic features differentiating between TS women non-45, $X$ and $45, X$ (1-7)

\begin{tabular}{lcc}
\hline & $\begin{array}{c}\text { Age at TS symptom } \\
\text { occurrence (years) }\end{array}$ & $\begin{array}{c}\text { Age at final TS } \\
\text { diagnosis (years) }\end{array}$ \\
\hline $\begin{array}{l}\text { A - TS women with } \\
\mathbf{4 5 , X} \text { monosomy }(\mathbf{n}=\mathbf{9 3})\end{array}$ & $\mathbf{6 . 8 1} \pm \mathbf{5 . 4 3}$ & $\mathbf{1 3 . 1 6} \pm \mathbf{7 . 9 7}$ \\
\hline $\begin{array}{l}\text { Childhood lymphoedema } \\
(\mathrm{n}=40)\end{array}$ & $5.81 \pm 5.77$ & $11.43 \pm 8.05$ \\
\hline $\begin{array}{l}\text { Finger deformity } \\
(\mathrm{n}=40)\end{array}$ & $6.79 \pm 4.94$ & $15.13 \pm 11$ \\
\hline $\begin{array}{l}\text { Posture defects } \\
(\mathrm{n}=69)\end{array}$ & $7.5 \pm 5.29$ & $13.33 \pm 7.41$ \\
\hline $\begin{array}{l}\text { Low posterior hairline } \\
(\mathrm{n}=91)\end{array}$ & $7.45 \pm 5.64$ & $13.71 \pm 8.92$ \\
\hline $\begin{array}{l}\text { Neck anomalies } \\
(\text { short, webbed) }(\mathrm{n}=85)\end{array}$ & $7.42 \pm 5.6$ & $13.76 \pm 8.72$ \\
\hline $\begin{array}{l}\text { Induced puberty } \\
(\mathrm{n}=83)\end{array}$ & $7.28 \pm 5.66$ & $13.1 \pm 6.65$ \\
\hline $\begin{array}{l}\text { Induced menorrhoea } \\
(\mathrm{n}=119)\end{array}$ & $7.96 \pm 5.64$ & $14.15 \pm 7.29$ \\
\hline $\begin{array}{l}\text { B - TS women non-45,X } \\
(\mathbf{n}=\mathbf{6 4})\end{array}$ & $\mathbf{1 0 . 2 7 \pm 5 . 1 8}$ & $\mathbf{1 7} \pm \mathbf{8 . 1 9}$ \\
\hline
\end{tabular}

deformities, as well as induced puberty and menorrhoea were comparable with the mean age at symptom occurrence and final diagnosis in TS patients with 45 , X monosomy (Tab. III).

\section{Discussion}

Despite the progress in diagnostic techniques, the findings elicited on history taking and physical examination remain the common ground of information exchange between specialists in different medical fields. Although this kind of message prove to be subjective or sketchy, it should convey the general impression obtained during a patient-doctor encounter. The results obtained by the same medical team should be comparable.

Thirty-seven non-gynaecological TS features (including body height) were selected for analysis based on literature determinations regarding differences between TS women and the general population. Our study revealed that only about $41 \%$ and $33 \%$ of these features occurred more frequently in the TS-women with 45,X monosomy and other karyotypes, respectively, compared to the controls. The question therefore arises: why not all 37 features? As mentioned in the Introduction section, the prevalence and severity of TS symptoms are highly variable. Clinical manifestations found in TS females can be attributed to chromosome $X$ abnormality or gonadal dysgenesis. Treatment-related symptoms cannot be excluded either.

Hormone therapy in TS patients comprises not only a treatment for short stature (growth hormone) and compensation for sex hormone deficit (sex hormones), but also a counteraction to the effects of this deficit, including the reduction in the risk of cardiovascular disease [12, 21]. Long-term pleiotropic effects of the growth hormone should be kept in mind as well as the fact that they are not always predictable [22]. The proportion of patients acknowledging childhood application of growth hormone and current use of HRT was much lower than expected (as already noted in our previous publications) [23]; nevertheless, the consequences thereof cannot be ruled out. Comparable proportions of patients admitting paediatric growth hormone and current HRT application indicated that differences in the occurrence of some clinical features in $45, \mathrm{X}$ monosomy and other karyotypes might result from the loss of the genetic material from the $X$ chromosome. The longitudinal study by Lebenthal et al. provides unique insights into the evolution of weight gain and metabolic disorders from childhood to early adulthood in TS patients. The occurrence of metabolic comorbidities was similar in $45, \mathrm{X}$ monosomy and other karyotypes, while co-occurrence of multiple metabolic comorbidities was significantly higher in $45, \mathrm{X}$ monosomy. Because overweight and increasing age aggravate the risk of metabolic comorbidities, careful surveillance is warranted to prevent and control obesity from childhood through adulthood. The authors concluded that the more prominent clustering of metabolic comorbidities in $45, X$ monosomy underscores the importance of a more vigorous intervention in this group [15].

We are now going to analyse the parameters whose prevalence or mean values were significantly different between the study groups. Prior to that, however, the non-occurrence of statistically significant differences in body height should be commented upon. Short stature phenotype is characteristic of TS. The average height of adult women with 45,X and 45,X/46,XX karyotype is $140-142 \mathrm{~cm}$ and $147 \mathrm{~cm}$, respectively [24, 25]. Our study participants with $45, \mathrm{X}$ monosomy were not shorter than those with non- $45, X$ karyotypes. It can therefore be speculated that, in women with $45, X$ monosomy or some of them at least, growth impairment does not necessarily result from the loss of genetic material. The lack of differences regarding the prevalence of the non-differentiating clinical features (ENT, ophthalmic, maxillofacial, dermatological, urology and nephrology, cardiology, endocrine-obstetric-gynaecological) in the two TS groups could be similarly interpreted. However, the magnitude of $X$-chromosome material deficit in $45, X$ patients is hard to determine. Genetically, pure 
$45, \mathrm{X}$ monosomy is considered lethal. Although not yet proven, it is believed that patients with $45, X$ karyotype have some degree of mosaicism to maintain viability. According to some authors, clinical features are approximately in parallel with the magnitude of the deficit of X-chromosome material [14].

As presented in the Results section, TS-women with $45, \mathrm{X}$ monosomy more frequently exhibited webbed neck, postural defects, finger/toe deformities, and low posterior hairline; childhood lymphoedema was also more frequently reported (all compared to TS women with other karyotypes). The prevalence of 19 of 23 endocrine-obstetric-gynaecological features (Tab. II) did not differ significantly between the two groups of women with TS. The differentiating features were: 1. pubertal induction, 2 . menarche induction, 3 . birth length, and 4. proportion of gynaecological surgeries.

Previous attempts to associate clinical features of with particular karyotypes did not lead to unambiguous conclusions. It should be emphasised that our study comprised 157 female participants examined by the same research team over a period of 20 years.

\section{Webbed neck}

Excess skin folds around the neck cause it to seem broad (webbed neck) and/or short [26, 27]. This anomaly is believed to result from subcutaneous nuchal oedema during foetal life, leading to nuchal skin redundancy, which can persist throughout life.

Similar to other dysmorphic features, webbing of the neck may be more or less prominent. Excess skin folds can be barely noticeable or of considerable width extending from the mastoid process and laterally to the acromion. Webbed neck was observed in over a half of our TS participants, which is consistent with literature data [11]. However, twice as many women with $45, X$ monosomy exhibited this feature compared to non- $45, \mathrm{X}$ TS women - a finding unaccounted for by any other reports.

\section{Childhood lymphoedema}

Abnormal development of the lymphatic system may lead to lymphatic insufficiency, and, consequently, to hand and feet swelling. Lymph fluid stasis in the peripheral tissue typically produces chronic inflammation. Congenital lymphoedema occurs in over $80 \%$ of TS-girls. Savendahl and Davenport used lymphoedema as the key to diagnosis in $97 \%$ of the girls diagnosed with TS in infancy, while short stature was the key to diagnosis for $82 \%$ of the girls diagnosed in childhood or adolescence $[28,29]$. The proportion of our study participants who had clinically documented childhood lymphoedema was markedly lower. This clinical feature should be interpreted with caution because there were no medical records to verify the patient's statement. The significantly more frequent occurrence of childhood oedema in 45,X monosomy (Tab. I) could be attributed to the loss of some genetic material from the $\mathrm{X}$ chromosome.

\section{Finger/toe deformity}

Many of physical stigmata of TS result from structural bone defects [3]. Typically, females with TS have disproportionately short legs and an abnormal upper-to-lower segment ratio. Cervical vertebral hypoplasia contributes to short stature. Scoliosis may be present in approximately $10 \%$ of TS females, and approximately half have cubitus valgus or a wide carrying angle as a result of a developmental defect of the ulnar head. Similar abnormalities of the medial tibial and femoral condyles may also be present. Short metacarpals and metatarsals can result in finger and/or toe deformities. Around 20\% of our TS participants exhibited finger and toe deformities, which again was consistent with literature data [11]. However, the feature was significantly more prevalent among women with $45, \mathrm{X}$ monosomy.

\section{Postural defects}

Postural defects can be attributed, at least in part, to abnormalities in the growth of long (limbs) and short (spine) bones. The average height of adult women with $45, X$ and non- $45, X$ tends to differ significantly [24]. Forty per cent of the Turner syndrome population examined by Elder et al. [27] had excessive kyphosis. In our study faulty posture was found in a similar proportion of the TS participants but significantly more frequently in women with $45, \mathrm{X}$ monosomy.

\section{Low posterior hairline}

Individuals with Turner syndrome have a broad webbed neck and a low posterior hairline. Co-occurrence of these features might indicate a common underlying mechanism. Cabrol [5] observed low posterior hairline in approximately half of girls with TS, which is consistent with our results. However, the feature was significantly more prevalent in women with $45, \mathrm{X}$ monosomy.

\section{Pubertal induction and menarche induction}

Gonadal dysgenesis is a type of hypogonadism found in Turner syndrome [18]. Girls with TS typically present with primary amenorrhoea. Only a small proportion (approximately 10-16.5\%) are likely to have spontaneous menarche; subsequent menstrual cycles become irregular and tend to stop within 2-3 years. The mean age at menarche is 14 years [30]. In another study, $71 \%$ of TS women with pubertal induction had menarche at the mean age of 17.2 years [31]. Hagen et al. examined 
66 patients with TS; the prevalence of spontaneous puberty was $6 \%$ for $45, X$ and $54 \%$ for other karyotypes [32]. It is believed that spontaneous pubertal development is more common among girls with mosaic karyotypes compared to those with $45, \mathrm{X}$ monosomy. This is consistent with our findings. Puberty and menarche induction turned out to be among endocrine-obstetric-gynaecological features differentiating between our TS-groups.

\section{Gynaecological surgeries}

It should be noted that the proportion of gynaecological surgeries in TS-women with 45,X monosomy was lower than in those with other karyotypes.

\section{Birth length}

No statistically significant difference in body height was revealed between TS women with 45,X monosomy and those with other karyotypes. However, it should be emphasised that TS women with $45, \mathrm{X}$ monosomy had greater birth length than non- $45, X$ participants, but despite this initial advantage the lack of significant differences in adult body height between our study groups indicates slower growth and more severe short stature in TS women with 45,X monosomy.

Summing up it should be noted that although the above discussed abnormalities differ in prevalence or mean values (quantitative parameters), they all develop in tissues of mesodermal origin, which become the most affected by the loss of the genetic material. The molecular defect has not been characterised yet, but it has been hypothesised that deletion of a gene on the $X$ chromosome may be responsible for such connective tissue abnormalities (33). Out of 60 parameters analysed, nine were significantly more prevalent among TS women with $45, \mathrm{X}$ monosomy compared to their counterparts with other karyotypes. The majority of researchers report that more pronounced phenotypic features are associated with greater loss of genetic material observed in 45,X monosomy [14].

Gawlik et al. suggested that phenotype severity had an impact on time to diagnosis; hence, it is essential to emphasise the phenotypic variability of Turner syndrome [34].

Is it then worthwhile to try to identify clinical features differentiating between TS patients with different karyotypes? The mean age at symptom occurrence and final diagnosis of Turner syndrome differed significantly between the two subgroups of TS women. Hence, a question arises concerning the relationship between the presence of these differentiating symptoms in TS women and the age at final diagnosis of Turner syndrome [35].

The mean age at occurrence of TS symptoms and final diagnosis in all TS participants exhibiting the differentiating symptoms (presented in Tab. III) was comparable with the mean age at symptom occurrence and final diagnosis in TS patients with 45,X monosomy. Hence, the presence of the differentiating symptoms allows earlier diagnosis of Turner syndrome irrespective of the patient's karyotype.

\section{Conclusions}

1. The prevalence of the majority of the clinical manifestations of Turner syndrome does not differ between TS women with 45,X monosomy and those with non-45,X karyotypes.

2. Most clinical features differentiating women with TS with different karyotypes are more frequent in monosomy, but there are also those that are more common in women with TS, non-45,X.

3. Clinical manifestations, the prevalence of which differs between TS women with non-45,X karyotypes and $45, X$ monosomy, might help lower the age at diagnosis.

\section{Conflict of interest}

The authors declare that there is no conflict of interest that could be perceived as prejudicing the impartiality of the research reported. The results presented in this paper have not been published previously in whole or part, except in abstract form.

\section{Funding}

This research did not receive any specific grant from any funding agency in the public, commercial, or not-for-profit sector.

\section{Institution from which the paper originates}

Department of Health Promotion and Community Nursing, Faculty of Health Sciences, Medical University of Silesia and Department of Nephrology/ENDO Hospital of the Ministry of Interior and Administration, Katowice, Poland.

\section{References}

1. Gravholt $\mathrm{CH}$, Andersen $\mathrm{NH}$, Conway GS, et al. International Turner Syndrome Consensus Group. Clinical practice guidelines for the care of girls and women with Turner syndrome: proceedings from the 2016 Cincinnati International Turner Syndrome Meeting. Eur J Endocrinol. 2017; 177(3): G1-G70, doi: 10.1530/EJE-17-0430, indexed in Pubmed: 28705803.

2. Connor JM, Loughlin S. Molecular Genetics of Turner's Syndrome. Acta Paediatrica Sand. 1989; 78(Suppl): 77-80, doi: 10.1111/j.1651-2227.1989. tb11251.x, indexed in Pubmed: 2573230.

3. Lippe B. Turner Syndrome. Endocrinol Metab Clini North Am. 1991; 20(1): 121-152, doi: 10.1016/s0889-8529(18)30284-6, indexed in Pubmed: 2029883.

4. Zinn AR, Ross JL. Molecular analysis of genes on Xp controlling Turner syndrome and premature ovarian failure (POF). Semin Reprod Med. 2001; 19(2): 141-146, doi: 10.1055/s-2001-15394, indexed in Pubmed: 11480911.

5. Cabrol S, Chantot-Bastaraud S, Christin-Maitre S, et al. French Collaborative Young Turner Study Group. [Turner syndrome]. Ann Endocrinol (Paris). 2007; 68(1): 2-9, doi: 10.1016/j.ando.2006.12.002, indexed in Pubmed: 17320033 . 
6. Ogata T, Matsuo N. Turner syndrome and female sex chromosome aberrations: deduction of the principal factors involved in the development of clinical features. Hum Genet. 1995; 95(6): 607-629, indexed in Pubmed: 7789944

7. Gawlik A, Malecka-Tendera E. Transitions in endocrinology: treatment of Turner's syndrome during transition. Eur J Endocrinol. 2014; 170(2): R57-R74, doi: 10.1530/EJE-13-0900, indexed in Pubmed: 24225028.

8. Hall JG, Gilchrist DM. Turner syndrome and its variants. Pediatr Clin North Am. 1990; 37(6): 1421-1440, indexed in Pubmed: 2259547.

9. Miguel-Neto J, Carvalho AB, Marques-de-Faria AP, et al. New approach to phenotypic variability and karyotype-phenotype correlation in Turner syndrome. J Pediatr Endocrinol Metab. 2016; 29(4): 475-479, doi: 10.1515/jpem-2015-0346, indexed in Pubmed: 26812779.

10. Ackermann A, Bamba V. Current controversies in turner syndrome: Genetic testing, assisted reproduction, and cardiovascular risks. J Clin Transl Endocrinol. 2014; 1(3): 61-65, doi: 10.1016/j.jcte.2014.05.003, indexed in Pubmed: 29159084.

11. Ibarra-Ramírez M, Martínez-de-Villarreal LE. Clinical and genetic aspects of Turner's syndrome. Medicina Universitaria. 2016; 18(70): 42-48, doi: 10.1016/j.rmu.2016.03.003.

12. De Groote K, Demulier L, De Backer J, et al. Arterial hypertension in Turner syndrome: a review of the literature and a practical approach for diagnosis and treatment. J Hypertens. 2015; 33(7): 1342-1351, doi: 10.1097/HJH.0000000000000599, indexed in Pubmed: 26039527.

13. Jez W, Irzyniec T, Pyrkosz A. [Selected problems of the diagnosis of Turner's syndrome]. Przegl Lek. 2007; 64(3): 130-133, indexed in Pubmed: 17941463.

14. Cameron-Pimblett A, La Rosa C, King TFJ, et al. The Turner syndrome life course project: Karyotype-phenotype analyses across the lifespan. Clin Endocrinol (Oxf). 2017; 87(5): 532-538, doi: 10.1111/cen.13394, indexed in Pubmed: 28617979.

15. Lebenthal Y, Levy S, Sofrin-Drucker E, et al. The Natural History of Metabolic Comorbidities in Turner Syndrome from Childhood to Early Adulthood: Comparison between 45,X Monosomy and Other Karyotypes. Front Endocrinol (Lausanne). 2018; 9: 27, doi: 10.3389/fendo.2018.00027, indexed in Pubmed: 29479339.

16. Pinsker JE. Clinical review: Turner syndrome: updating the paradigm of clinical care. J Clin Endocrinol Metab. 2012; 97(6): E994-1003, doi: 10.1210/jc.2012-1245, indexed in Pubmed: 22472565.

17. Nielsen J, Wohlert M. Sex chromosome abnormalities found among 34,910 newborn children: results from a 13-year incidence study in Arhus, Denmark. Birth Defects Orig Artic Ser. 1990; 26(4): 209-239, indexed in Pubmed: 2090319.

18. Styne DM, Grumbach MM. Puberty: ontogeny, neuroendocrinology, physiology, and disorders. Pituitary physiology and diagnostic evaluation. In: Melmed S, Polonsky KS, Reed Larsen P, Kronenberg HM. ed. Williams Textbook of Endocrinology, 12th ed. Saunders Elsevier, Philadelphia 2011: 1054-1201.

19. Moussaif NEl, Haddad N, Iraqi N, et al. $45, X / 46, X Y$ mosaicisme: Report of five cases and clinical review. Annales d'Endocrinologie. 2011; 72(3): 239-243, doi: 10.1016/j.ando.2011.04.009, indexed in Pubmed: 21640978.
20. Frelich A, Frelich J, Jeż W, et al. Selected clinical features of the head and neck in women with Turner syndrome and the 45,X/46,XY karyotype. Endokrynol Pol. 2017; 68(1): 47-52, doi: 0.5603/EP.a2016.0063, indexed in Pubmed: 27828687.

21. Irzyniec TJ, Jeż W. A beneficial effect of estradiol on blood pressure, not on glucose and lipids levels in women with Turner syndrome. Arterial Hypertens . 2016; 20(4): 206-210, doi: 10.5603/AH.2016.0023.

22. Devesa J, Almengló C, Devesa P. Multiple Effects of Growth Hormone in the Body: Is it Really the Hormone for Growth? Clin Med Insights Endocrinol Diabetes. 2016; 9: 47-71, doi: 10.4137/CMED.S38201, indexed in Pubmed: 27773998.

23. Irzyniec TJ, Jeż W. The influence of hormonal replacement and growth hormone treatment on the lipids in Turner syndrome. Gynecol Endocrinol. 2014; 30(3): 250-253, doi: 10.3109/09513590.2013.872236, indexed in Pubmed: 24400597.

24. Fernandez R, Pasaro E. Tall stature and gonadal dysgenesis in a non-mosaic girl 45,X. Horm Res Paediatr. 2010; 73(3): 210-214, doi: 10.1159/000284364, indexed in Pubmed: 20197675

25. Hjerrild BE, Mortensen $\mathrm{KH}$, Gravholt $\mathrm{CH}$. Turner syndrome and clinical treatment. Br Med Bull. 2008; 86(6): 77-93, doi: 10.1093/bmb/ldn015 indexed in Pubmed: 18400842.

26. Berdahl LD, Wenstrom KD, Hanson JW. Web neck anomaly and its association with congenital heart disease. Am J Med Genet. 1995; 56(3): 304-307, doi: 10.1002/ajmg.1320560318, indexed in Pubmed: 7778596.

27. Elder DA, Roper MG, Henderson RC, et al. Kyphosis in a Turner syndrome population. Pediatrics. 2002; 109(6): e93, indexed in Pubmed: 12042587.

28. Loscalzo ML, Van PL, Ho VB, et al. Association between fetal lymphedema and congenital cardiovascular defects in Turner syndrome. Pediatrics. 2005; 115(3): 732-735, doi: 10.1542/peds.2004-1369, indexed in Pubmed: 15741379.

29. Sävendahl L, Davenport ML. Delayed diagnoses of Turner's syndrome: proposed guidelines for change. J Pediatr. 2000; 137(4): 455-459, doi: 10.1067/mpd.2000.107390, indexed in Pubmed: 11035820.

30. Jeż W, Cybulska D, Buliński A, Jarząb B, Jarząb J. Zespół Turnera. Termedia Wydawnictwa Medyczne, Poznań 2010: 58-63.

31. Jeż W, Żarów R, Brudecki J, et al. Menarche u dziewcząt z zespołem Turnera. Ann UMCS Sect D. 2006; 3(Suppl 16): 55-58.

32. Hagen CP, Main KM, Kjaergaard S, et al. FSH, LH, inhibin B and estradiol levels in Turner syndrome depend on age and karyotype: longitudinal study of 70 Turner girls with or without spontaneous puberty. Hum Reprod. 2010; 25(12): 3134-3141, doi: 10.1093/humrep/deq291, indexed in Pubmed: 20956269

33. Elsheikh M, Dunger DB, Conway GS, et al. Turner's syndrome in adulthood. Endocr Rev. 2002; 23(1): 120-140, doi: 10.1210/edrv.23.1.0457, indexed in Pubmed: 11844747.

34. Gawlik A, Gawlik T, Małecka-Tendera E, et al. [The influence of phenotypic expression on the age at diagnosis in Turner syndrome]. Pediatr Endocrinol. 2006; 5(2): 23-30.

35. Lee MC, Conway GS. Turner's syndrome: challenges of late diagnosis. Lancet Diabetes Endocrinol. 2014; 2(4): 333-338, doi: 10.1016/S2213-8587(13)70153-0, indexed in Pubmed: 24703051. 